\title{
KUTTAB SEBAGAI PENDIDIKAN DASAR ISLAM DAN PELETAK DASAR LITERASI
}

\author{
Novianti Muspiroh \\ Staf pengajar Institut Agama Islam Negeri Syekh Nurjati Cirebon dan mahasiswa Program \\ Doktoral Pendidikan Dasar Universitas Negeri Jakarta \\ noviantimuspiroh.ak@gmail.com
}

\begin{abstract}
Abstrak
Kajian sejarah mengenai lembaga pendidikan selama ini lebih banyak terfokus kepada madrasah. Padahal kuttab adalah salah satu lembaga pendidikan yang tidak kalah pentingnya. Kuttab merupakan pendidikan dasar untuk anak-anak usia dini dan yang terpinggirkan. Keberadaannya sudah ada sejak sebelum Islam sampai terutama dengan kemunculan madrasah, meskipun selanjutnya tetap bertahan dalam lingkup yang terbatas. Sebagai lembaga pendidikan, kuttab menunjukkan peran yang sangat penting bagi pendidikan anak-anak khususnya dalam literasi dan pendidikan dasar agama. Meskipun sistem pendidikan ini bersifat tradisional, namun kuttab sangat berperan dalam membangun literasi yang baik bagi masyarakat Islam terutama di awal-awal sejarah Islam. Pendekatan yang digunakan antara lain keteladanan dan pembiasaan. Model pembelajarannya halaqoh.
\end{abstract}

Keywords: Character building, Marginal, Traditional, non-formal

\section{A. Pendahuluan}

Islam sudah mengenalkan konsep pendidikan dasar atau pendidikan anak usia dini pada umatnya, yang dinamakan Kuttab. Kuttab ialah insitusi pendidikan dasar Islam yang memiliki sejarah panjang melahirkan tokoh-tokoh besar. Seiring hilangnya kuttab dari dunia Islam, bumi pun mulai kehilangan cahaya dari para ilmuwan dan ulama. Dahulu Kuttab mengukir lahirnya karya-karya ilmiah yang abadi sampai hari ini, disebutkan dengan terperinci di tanah Mekah dan Madinah, dan melahirkan ulamaulama yang menjadi rujukan institusi-institusi Islam zaman ini. Catatan historis mengenai Kuttab masih tersimpan dengan rapih. Rujukan dan penerapan di lapangan tersusun dengan sempurna. Kriteria pengembangan dan pengelola institusi terkonsep dengan baik. Bahkan kurikulumnya pun dijelaskan tanpa ada yang tertutupi. 
Kalau menurut merujuk periodisasi sejarah pendidikan Islam klasik, kemunculan kuttab ini adalah kelompok lembaga-lembaga pendidikan sebelum kemunculan madrasah $^{1}$. Madrasah yang dimaksud adalah madrasah Nidzamiyah. Sebab kemunculan madrasah dipandang sebagai tonggak baru dalam penyelenggaraan pendidikan Islam. Walaupun demikian lembaga-lembaga pendidikan sebelum madrasah ini tetap dipakai sesuai dengan sifat tradisionalnya sekalipun jumlah dan peminatnya sedikit. ${ }^{2}$

\section{B. Eksistensi Kuttab}

Mempelajari perkembangan institusi Pendidikan Islam, tentulah dimulai dari institusi Pendidikan Islam yang pertama kali ada, yakni kuttab. Kuttab adalah pusat pengajaran paling tua di kalangan orang-orang Islam. Ada yang mengatakan dunia Arab sudah mengetahuinya sebelumnya sebelum kedatangan Islam. Akan tetapi, hal itu hanya dalam wilayah yang terbatas, sebab mayoritas masyarakat Arab buta huruf dan kurang tertarik mengembangkan pendidikan. Meskipun diantara mereka terutama penduduk Hijaz ada yang sudah mengenal membaca dan menulis. Mereka belajar kemampuan ini dari orang-orang Hirah. Sementara orang-orang Hirah mendapatkannya dari Himyariyin. $^{3}$

Nama kuttab sebagai lembaga pendidikan sudah dikenal di kalangan bangsa Arab sebelum Islam dan seperti sebelumnya kuttab menjalankan fungsi yang sama dalam Islam, yakni sebagai lembaga pendidikan dasar. Tujuan pendidikan kuttab adalah sebagai pendidikan dasar dalam memberikan persamaan pengajaran anak-anak kaum muslimin dalam hal membaca menulis, dan menghapal al-Qur'an.

Ketika Islam datang hanya terdapat 17 orang Quraisy yang bisa tulis dan baca. Di antara penduduk Mekah yang pertama-tama menulis membaca huruf Arab adalah Abu Qais Abdul Manaf bin Zuhrah bin Kilab dan Sufyan bin Umayyah bin Abdul Syams. Keduanya belajar dari guru Bisyr bin Abdul Malik yang mempelajarinya di negara Hirah. Di tengah pertentangan dengan qabilah Quraisy, tidak banyak yang bisa

\footnotetext{
${ }^{1}$ Lembaga-lembaga pendidikan ini, yaitu Kuttab, Qushur, Hawamit al-Waraqin, Manazil al-Ulama, alBadiyah. Lihat Ahmad Syalabi. Al-Tarbiyah al-Islamiyah, Nuzumuha, Falsafatuha, Tarikhuha. (Kairo: Maktabah al-Nahdah al-Mashriyah, 1987), h. 43

${ }^{2}$ Ibid.

${ }^{3}$ Yunus, loc cit.
} 
dilakukan oleh Rasulullah saw bersama pengikut-pengikutnya yang hanya berjumlah sedikit. Saat akhirnya umat Islam hijrah ke Madinah (622 M.) sejumlah orang dari suku Aws dan Khazraj (dua suku utama Madinah yang awalnya saling bermusuhan) bisa baca dan tulis.

Kedudukan kuttab di abad pertama hijriyah ini merupakan prioritas yang sangat diperhatikan urusannya oleh Rasulullah ,sebab merupakan gerbang pintu menuju pengajaran yang lebih tinggi. Beliau menaruh konsern yang besar terhadap masalahmasalah pendidikan. Kuttab seperti madrasah ibtidaiyah pada masa sekarang. Kemampuan membaca dan menulis yang merupakan pembelajaran inti dalam lembaga pendidikan kuttab, menjadi semakin urgen selaras dengan perkembangan agama dan umat Islam di Madinah. Kebutuhan yang sangat penting saat itu ialah pencatatan wahyu yang diterima oleh Nabi Muhammad saw. Akan tetapi keterampilan membaca dan menulis tersebut juga diperlukan untuk memungkinkan berjalannya komunikasi antara kaum muslimin dengan suku-suku dari bangsa lain. Peletakan keterampilan membaca dan menulis sebagai program pendidikan prioritas bisa dilihat dalam peristiwa pembebasan tawanan-tawanan Perang Badr (2/624). Rasulullah saw memberi keputusan terhadap tawanan perang Badar agar mereka menebus dengan harta, akan tetapi para tawanan tidak memilikinya, maka selanjutnya mereka diperintah untuk mengajarkan 12 anak-anak orang Islam sebagai kompensasinya. ${ }^{4}$ Setelah itu, Beliau juga menginstruksikan al-Hakam bin Sa'id untuk menjadi staf pengajar pada sebuah kuttab di Madinah. Ini memperlihatkan bahwa pendidikan sudah menjadi perhatian penting kaum muslimin sejak masa yang paling awal.

Awalnya, pendidikan kuttab diselenggarakan di rumah-rumah guru-guru (mu'addib, mu'allim), rumah-rumah para penghafal al-Qur'an, berada di masjid atau pekarangan di sekitar masjid. ${ }^{5}$ Darinya muncullah ulama-ulama besar fikih dan penghafal al-Qur'an. Materi yang disampaikan adalah pelajaran tulis-baca ini secara umum ialah pepatah-pepatah dan puisi Arab yang memiliki nilai-nilai tradisi yang baik.

\footnotetext{
${ }^{4}$ Sirjani Raghib As-. 2011. Sumbangan Peradaban Islam Pada Dunia. (Jakarta: Pustaka Al-Kautsar, 2011), h. 203

${ }^{5}$ Clifford Edmund Bosworth, M. S. Asimov.The Age of Achievement: A.D. 750 to the End of the Fifteenth Century : The Achievements: History of Civilizations of Central Asia. Paris, France: UNESCO 2000, h. 33-4,
} 


\section{Novianti Muspiroh}

Materi mengenai al-Qur'an disampaikan di dalam kuttab baru terjadi kemudian, saat jumlah umat Islam yang menguasai al-Qur'an sudah banyak, khususnya sesudah dilakukan pengumpulan dan pembukuan al-Qur'an pada pemerintahan khalifah Utsman bin 'Affan. Sebagian besar guru kuttab ketika permulaan Islam adalah orang-orang yang bukan Islam, karena yang bisa membaca dan menulis yang jumlahnya masih sangat sedikit, mereka masih lebih memprioritaskan pencatatan ayat-ayat al-Qur'an. Kuttab saat itu belum mendapatkan perhatian yang cukup dari pemerintah Islam. Namun orangseiring dengan meluasnya kekuasaan Islam orang Islam mempunyai semangat yang tinggi agar anak-anak dapat mempelajari al-Qur'an. Mereka menganggap mengajarkan al-Qur'an adalah suatu pekerjaan yang bernilai ibadah, terhormat, dan mulia. sehingga orang berlomba-lomba mendirikannya. Keadaan ini menjadikan kuttab semakin berkembang pesat. Sebagai contoh Ibnu Hauqal ${ }^{6}$ mendirikan 300 kuttab di satu kota negeri Shaqilah. ${ }^{7}$ Setelah abad kedua hijriyah, di desa-desa kecil di wilayah Persia telah diwajibkan mengirim anak-anak ke kuttab secara teratur tanpa campur tangan pemerintah. ${ }^{8}$

Nama kuttab berasal dari kata taktib yang berarti mengajarkan menulis. Ada pula yang mengatakan bahwa kuttab atau maktab berasal dari kata kataba yang bermakna menulis atau tempat menulis. Jadi kataba ialah tempat belajar menulis. ${ }^{9}$ Sedangkan kuttab atau katib berarti penulis. Dalam penggunaan Bahasa Arab Modern yang umum, kuttab berdekatan dengan kata maktab yang berarti "kantor", sementara maktabah berarti "perpustakaan" atau "(tempat belajar)" dan kuttāb adalah kata jamak yang berarti "buku". ${ }^{10}$ Lembaga pendidikan ini hanya berupa tempat belajar baca tulis untuk anakanak. Pada perkembangannya, nama kuttab dipakai dalam menyebutkan tempat untuk mengajari al-Qur'an untuk anak-anak. Lembaga pendidikan al-Qur'an ini sebaga lembaga yang efektif bagi anak-anak. Di mana dengan metode yang selaras dengan jiwa

\footnotetext{
${ }^{6}$ Nama lengkapnya Abu Qasim Muhammad bin Hauqal (350 H). Seorang pengembara, ahli geografi dan sejarah. Karyanya yang terkenal adalah ta'liq wa tanqih li kitab al masalik wa al mamalik li isthakhrawi.

${ }^{7}$ Sirjani, op cit, h. 203.

${ }^{8}$ Asma Hasan Fahmi. Sejarah dan Filsafat Pendidikan Islam. (Jakarta: Bulan Bintang, 1979), h. 31-32

${ }^{9}$ Mahmud Yunus. Sejarah Pendidikan Islam: Dari Zaman Nabi Muhammad saw Khalifah-khalifah Rasyidin, Umaiyah dan Abbasiyah sampai Zaman Mamluks dan Usmaniyah Turki. (Jakarta: PT. Hidakarya Agung, 1990), h. 19.

${ }^{10}$ Bosworth, op cit, h. 34 .
} 
anak-anak bisa menjadikan metode pembelajaran di kuttab menjadi menyenangkan. Pada sisi inilah yang menjadikan kuttab sebagai model pembelajaran di dunia pendidikan Islam. ${ }^{11}$

Terkadang kata kuttab disamakan dengan maktab. Namun tidak ada kejelasan apakah kedua istilah tersebut dipakai secara simultan. George Makdisi membedakan dua bentuk pendidikan dasar ini. Dia mengatakan bahwa maktab berbeda dengan dengan kuttab, palling tidak di Nisapur. Untuk memperkuat pendapatnya, Makdisi melaporkan bahwa Abd al-Ghafir al-Farisi belajar di maktab pada usia lima tahun untuk belajar al-Qur'an dan ilmu agama di Persia. Selanjutnya, ia menjelaskan bahwa ada laporan bahwa maktab adalah sekolah tingkat dasar yang mengajarkan khat, kaligrafi, al-Qur'an, akidah dan syair. ${ }^{12}$

Kuttab sesungguhnya sudah pada bangsa Arab sebelum Islam datang disampaikan Rasulullah saw. Dapat diumpamakan juga dengan pesantren di Pulau Jawa. Keadaannya masih sangat sederhana, hanya beralas karpet dan papan meja, muhsaf al-Qur'an, buku hingga pena. Model pembelajarannya adalah model halaqah dimana guru mengajarkan murid-murid yang berada di sekeliling mengitarinya. Para guru duduk di atas kursi, dan terkadang kursi diganti dengan lantai yang lebih tinggi. ${ }^{13}$

Sejarah permulaan pendidikan Islam mencatat bahwa kuttab terbagi ke dalam dua karakteristik, yakni: Pertama, kuttab berfungsi sebagai institusi pendidikan yang memusatkan perhatian kepada baca tulis, menghapal al-Qur'an, ilmu dasar agama, dan berhitung dasar, dalam teori pendidikan modern, membaca (qiraah) dan menulis (kitabah) merupakan teori kemampuan dasar pendidikan. Kuttab ini sering juga disebut dengan kuttab awwal. Kedua, kuttab sebagai institusi pendidikan yang mengajarkan ilmu bahasa dan adab, dasar-dasar ilmu-ilmu agama, hadits. Jenis kuttab ini sering juga disebut kuttab qonuni. ${ }^{14}$

\footnotetext{
${ }^{11}$ M. Mukhlis Fahrussin. "Kuttab: Madrasah pada Masa Awal (Umayyah) Pendidikan Islam”, dalam Jurnal Madrasah. Vol. II, No. 2 Januari-Juni. 2010. h. 217.

${ }^{12}$ George Makdisi. “ Typology of Institution of Learning”, dalam al-Anthology Studies oleh Issa J. Baulatta. (Montreal: McGill Indonesia IAIN Development Project, 1992), h. 16.

${ }^{13}$ Muhammad ibnu Sahnun. Adab al-Mu'allim. (Dar al-Lu'luh, 256H), 50.

${ }^{14}$ Amir Jad Allah Abu Jabalah. Tarikh al-Tarbiyah wa-al-Ta'lim fi Sadr al-Islam. (al-Mu allif, 1998), h. 110.
} 
Di antara penduduk Mekah yang pertama kali belajar menulis huruf Arab di kuttab ini yakni Abu Qais Abdul Manaf bin Zuhrah bin Kilab dan Sufyan bin Umayyah bin Abdul Syams. Mereka berdua diajar oleh Bisyr bin Abdul Malik, seorang guru dari Hirah. Bentuk awal dari Kuttab hanya berupa ruangan di rumah seorang muallim.

Keunikan kuttab adalah walaupun masih sangat sederhana dan tradisonal, namun memberikan sumbangan bagi kaum muslimin sampai berdirinya pendidikan model madrasah pada abad-abad selanjutnya. Pendidikan model kuttab ini awalnya diselenggarkan di rumah-rumah para mu'alim atau muaddib. ${ }^{15}$ Sesudah Rasulullah saw dan sahabat-sahabat mendirikan masjid, barulah terdapat kuttab yang didirikan di samping masjid. Disamping itu ada pula kuttab yang didirikan secara terpisah dari masjid. Masa pendidikan di Kuttab tidak ditentukan, tergantung kepada kondisi siswa. Siswa yang rajin dan cerdas, akan lebih cepat menyelesaikan pelajarannya. Sebaliknya anak yang malas, maka akan membutuhkan waktu yang lama untuk menyelesaikan pelajarannya. Tidak ada sistem klasikal di dalamnya. Para murid umumnya duduk berkeliling dan bersila (halaqah) menghadap ke arah guru.

Dalam tradisi kuttab, apabila siswa selesai menghafal al-Qur'an, maka diselenggarakan suatu perayaan yang dinamakan dengan israfah. Ketika itu siswa dinaikkan kuda yang sudah dihias, dan di belakangnya, teman-temannya ikut mengarak, dari kuttab menuju ke rumahnya. Sesampainya di rumah, orang tua siswapun menyambutnya sedangkan siswa tersebut juga membawa lembaran yang memperlihatkan dia sudah selesai belajar di kuttab. Selanjutnya orang tua pun memberi hadiah materi kepada pendidik.

Kuttab pada masa pemerintahan Dinasti Abbasiyah memanfaatkan ruanganruangan masjid sebagai sarana belajar menulis (kitabah) dan membaca (qiraah) alQur'an. Kuttab sebagai tempat belajar bagi anak-anak tidak hanya bertempat di rumah. Namun, juga di pinggir-pinggir pasar, toko-toko, dan bahkan di istana. Adapun pengajarannya mencakup membaca al-Qur'an dan menghafalnya, pokok-pokok Nahwu-

\footnotetext{
${ }^{15}$ Menurut Said Ahmad menjelaskan kata Muaddib ada pada deretan tingkat istilah pengajar pada masa Umawi disamping istilah muallim, mudarris, mu'id, syaikh, faqih, dan ustadz. Muaddib adalah guru-guru privat di rumah-rumah dan istana-istana. Lihat Hassan Muhammad Hassan dan Nadiyah Jamaluddin. Madaris al-Tarbiyahfi'al-Hadarah al-Islamiyah. (Kairo: Dar al-Fikr al-Arabi, 1984), h.194.
} 


\section{Novianti Muspiroh}

Shorof, berhitung, menghafal syair-syair atau prosa, menulis, membaca, dan pokokpokok ajaran Islam sejarah orang-orang besar Islam.

Anak-anak belajar di kuttab beralaskan seperti tikar atau karpet, tempat mereka duduk bersila di dekat guru mereka. Peralatan belajar mereka terdiri dari pena, tinta, papan kayu untuk menulis, dan Mushaf al-Qur'an. Sedangkan guru duduk di atas kursi atau alas yang lebih tinggi dari alas murid-muridnya (halaqah).

Seiring dengan kemajuan peradaban Islam, lembaga-lembaga pendidikan lain mulai mengarahkan dirinya terhadap pendidikan Islam dan berdirilah Dar al-Hikmah ${ }^{16}$ yang merupakan lembaga riset, perpustakaan dan penerjemahan karya-karya asing terutama Yunani ke dalam Bahasa Arab. Setelah itu lahirlah sistem madrasah yang menjadikan sistem pendidikan Islam memasuki periode baru dalam perkembangan dan pertumbuhannya, dimana periode ini ialah periode terakhirnya. Karena di sini madrasah sudah merupakan salah satu lembaga pendidikan formal negara dimana dikeluarkannya pegawai-pegawai dan pekerja-pekerja negara. Munculnya institusi Madrasah memainkan peran mendasar dalam tingkat melek huruf atau pertumbuhan literasi yang relatif tinggi dari dunia Islam abad pertengahan. ${ }^{17}$

\footnotetext{
${ }^{16}$ Bait al-Hikmah (The House of Wisdom) adalah akademi dan pusat intelektual Abbasiyah yang penting di Baghdad, sebagai lembaga riset, penerjemahan dan perpustakaan besar kepunyaan Khalifah Abbasiyah selama masa Keemasan Islam. Banyak terjemahan dilakukan dalam bidang astrologi, matematik, pertanian, perubatan, filsafat, dan lain-lain. Lihat Dimitri Gutas. Greek Thought, Arabic Culture: The Graeco-Arabic Translation Movement in Baghdad and Early 'Abbāsid Society (2nd-4th/8th-10th Centuries). (London, United Kingdom: Psychology Press, 1998), h. 53-60: Jim Al-Khalili. 5: The House of Wisdom. The House of Wisdom: How Arabic Science Saved Ancient Knowledge and Gave Us the Renaissance. (London, United Kingdom: Penguin Publishing Group, 2011). h. 53. Pormann, Peter E.; Savage-Smith, Emilie. Medieval Islamic Medicine. (Washington, D.C.: Georgetown University Press, 2007), h. 20-29. Perpustakaan ini didirikan oleh Khalifah Harun al-Rasyid dan mencapai kejayaannya di masa kepemimpinan putranya, Khalifah al-Ma'mun yang berkuasa pada 813-833 M yang mana perpustakaan ini disematkan sebagai usahanya. Al-Ma'mun juga diakui usahanya dalam memunculkan banyak ilmuwan terkenal untuk saling berbagi informasi, pandangan dan budaya di Dar al-Hikmah. Berpusat di Baghdad sepanjang abad ke-9 hingga ke-13, terdapat banyak ilmuwan di sana termasuk diantaranya orang-orang dengan latar belakang Persia ataupun Kristen yang ikut ambil bagian pada penelitian dan pendidikan di institusi ini. Selain menerjemahkan buku-buku asing ke dalam Bahasa Arab, para ilmuwan yang memiliki hubungan dengan Dar al-Hikmah juga banyak membuat kontribusi asli yang besar di berbagai bidang. Lihat Hyman and Walsh. Philosophy in the Middle Ages, (Hackett Publishing: Indianapolis, 2010), h. 204; Josef W. Meri, Jere L. Bacharach. Medieval Islamic Civilization: An Encyclopedia. (Abingdon, United Kingdom: Routledge, 2006), h. 304.

${ }^{17}$ Andrew J. Coulson, Delivering Education. (California, USA, Stanford University: Hoover Institution), h. 117; Edmund Burke, "Islam at the Center: Technological Complexes and the Roots of Modernity", dalam Journal of World History, University of Hawaii Press, 20 (2), June 2009: 165-186.
} 
Kuttab sebagai lembaga pendidikan dasar Islam pertama akhirnya digantikan dengan sistem baru ketika Nidzam al-Mulk ${ }^{18}$ (w. 1092 H/485 M) mendirikan madrasah Islam pertama di kota Baghdad pada tahun 1066 M. Madrasah Nidzamiyah didirikan memakai metode dan sistem yang lebih maju jika dibandingkan kuttab. Di kemudian hari Madrasah Nidzamiyah menjadi model bagi madrasah-madrasah Islam yang diselenggarakan di Mosul, Basrah, Marv, Isfahan, Heart, Balkh, dan Nisabur. ${ }^{19}$ Institusi ini berperan sekali dalam penyebaran faham sunni. ${ }^{20}$ Meskipun demikian lembaga pendidikan sebelumnya, seperti masjid, kuttab, pendidikan tinggi dar al-hikmah, dar alilmu, bimaristan masih eksis sebagai lembaga pendidikan di kota-kota muslim hingga menjelang era modern. Demikian pula, usaha-usaha pribadi ulama dan guru sufi dalam melaksanakan aktivitas pendidikan tetap berlangsung. ${ }^{21}$

\section{Tujuan Pendidikan Kuttab}

Tujuan yang hendak dicapai oleh pendidikan kuttab, yaitu:

1. Tujuan keagamaan

Anak-anak bisa menghafal al-Qur'an dan mengetahui artinya sehingga anak mempunyai perbendaharaan taqwa, kesucian, dan petunjuk yang sangat berharga.

2. Tujuan pembentukan budi pekerti

\footnotetext{
${ }^{18}$ Nidzham al-Mulk (lahir 10 April 1018 - wafat 14 Oktober 1092), adalah seorang perdana menteri atau wazir Kesultanan Bani Saljuk dan cendekiawan keturunan Persia. Nama aslinya adalah Abu Ali al-Husain bin Ali bin Ishaq bin al-Abbas al-Thusi. Dia menjabat perdana menteri pada masa pemerintahan Alp Arslan dan Malik Syah I. Pada masa Nizham al-Mulk inilah faham Asy'ariyah menjadi kuat berkembang sebab dijadikan aliran resmi negara, dan keilmuan al-Ghazali mendapat dukungan penuh darinya. Ia memegang kekuasaan selama 20 tahun semenjak meninggalnya Alp Arslan pada tahun 1072. Lihat Corbin, Henry. History Of Islamic Philosophy. (Abingdon, United Kingdom: Routledge, 2014). h. 119; Gustave E. Von Grunebaum, Katherine Watson. Classical Islam: A History, 600 A.D. to 1258 A.D., diterjemahkan oleh Katherine Watson. (Piscataway, New Jersey: Aldine Transaction, 2005), h. 155; Holt, P. M., Ann K. S. Lambton, Bernard Lewis. The Cambridge History of Islam Volume 1. (Cambridge, UK: Cambridge University Press, 1977), h. 150; Panji Masyarakat. Yayasan Nurul Islam. 1997. h. 160-161; Gibb, H. A. R. (1960-1985). The Encyclopedia of Islam, vol. 8. (Leiden: Brill), h. 70.

${ }^{19}$ Moh. Toriqul Chaer. 2015. "Kuttab, Lembaga Pendidikan Islam Klasik”, dalam Jurnal al-Murabbi, Vol. 01 No. 02, Januari-Juni 2015

${ }^{20}$ Francis Robinson, "Review: Law and Education in Medieval Islam: Studies in Memory of Professor George Makdisi”, dalam Journal of the Royal Asiatic Society, diedit oleh Joseph E. Lowry, Devin J. Stewart and Shawkat M. Toorawa. Cambridge University Press, 18 (01) 2008: 98-100,

${ }^{21}$ Hisham Nashabe. Muslim Educational Institution. (Beirut: Librarie De Liban, 1989), h. 25.
} 
Dengan sugesti dari keteladanan dalam sikap, nasehat-nasehat, dan syair-syair maka pembentukan karakter anak-anak yang diharapkan dapat mencontoh perilaku baik orang-orang saleh.

3. Tujuan manfaat

Ilmu hitung, tata bahasa nahwu, ilmu politik (ilmu akhbar), dan sebagainya diharapkan dapat memberi bekal nilai-nilai praktis dalam kehidupan sehari-hari. ${ }^{22}$

\section{Kurikulum Pendidikan Kuttab}

Kurikulum pendidikan kuttab memuat ilmu-ilmu yang diajarkan pada mulanya sederhana saja, yakni: 1) Belajar menulis dan membaca, 2) Membaca al-Qur'an dan menghafalkannya, 3) Belajar pokok-pokok ajaran agama Islam, seperti puasa, cara berwudhu, sholat, dan sebagainya.

Selanjutnya pada zaman pemeriantahan Khalifah Umar bin Khattab, beliau mengintruksikan kepada penduduk-penduduk kota agar mengajarkan juga menghafal syair-syair dan peribahasa, membaca, memanah, mengendarai kuda, dan berenang. Kebijakan khalifah Umar direspon di sejumlah kota yang mempunyai sungai seperti Mesir, Irak, dan lain-lain. ${ }^{23}$

Beberapa kuttab semakin berkembang dengan mengajarkan materi al-Qur'an, tata bahasa, ilmu hitung, bahasa, pokok-pokok agama, dan menulis. Akan tetapi setiap kuttab tidak memperlihatkan kesamaan dalam menyampaikan materi pelajaran. Contoh saja umat Islam di Maroko sangat memfokuskan pengajaran al-Qur'an. Muslim Spanyol memfokuskan pelajaran membaca dan menulis. Daerah Ifriqiyah menekankan kepada belajar al-Qur'an dengan fokus khusus pada keragaman bacaan. Wilayah Timur menganut perpaduan kurikulum dengan al-Qur'an sebagai inti, namun tidak mengintegrasikan dengan keterampilan kaligrafi, sehingga tulisan anak-anak muslim dari Timur tidak cukup baik. ${ }^{24}$

\footnotetext{
${ }^{22}$ Fahmi, op cit, h. 70-73.

${ }^{23}$ Mahmud Yunus, op. cit, h. 40

${ }^{24}$ Tafsir, Ahmad., 2004. Cakrawala Pemikiran Pendidikan Islam. (Bandung: Mimbar Pustaka, 2004), h. 263.
} 
Kurikulum kuttab pada masa klasik memperlihatkan banyak hal berikut ini:

1. Meski tujuannya untuk belajar menulis dan membaca, akan tetapi pelajaran alQur'an menjadi topik penting di kuttab. Pelajaran al-Qur'an tidak hanya memenuhi aspek kognitif, tetapi juga afektif. Sehingga anak bisa mengapresiasi nilai-nilai alQur'an.

2. Pendidikan akhlak sangat diutamakan sebab merupakan aktualisasi dari al-Qur'an. Institusi pendidikan dianggap sebagai institusi penjaga moral. Sehingga umumnya, setiap pelajaran khususnya pelajaran agama, senantiasa mengandung muatan moral.

3. Pelajaran seni seperti musik dan tari tidak dikembangkan di kuttab. Kesenian ini dikhawatirkan bisa merusak akhlak anak.

4. Pelajaran lain di luar al-Qur'an seperti tata Bahasa Arab mungkin disampaikan sebagai media memahami al-Qur'an.

5. Pelajaran berhitung dan olahraga belum memperoleh keterangan yang rinci bagaimana materi dan pelaksanaanya di kuttab.

6. Tidak terlihat adanya pelajaran yang bisa dijadikan dasar pengembangan ilmu pengetahuan pada jenjang pendidikan selanjutnya. ${ }^{25}$

\section{E. Pendekatan dan Metode}

Metode pendidikan yang digunakan di kuttab ialah metode untuk membangun budi pekerti. Adapun cara yang diterapkan, yaitu:

1. Memberi pendekatan dan petunjuk, dengan cara menerangkan mana yang baik dan mana yang buruk, nasehat yang baik, cerita-cerita, dan menghafal syair-syair yang menganjurkan akhlak mulia dan budi pekerti. Sementara itu, guru mesti melarang mereka mempelajari syair-syair yang rendah mengenai orang yang bercinta dan percintaan. Hal ini tidak lain sebab syair tersebut berbahaya untuk pendidikan anak dan dalam membangun akhlak murid.

2. Memberikan pujian dan sanjungan. Anak-anak senang disanjung dan dipuji untuk memenuhi keinginan. Dorongan dan pujian lebih diutamakan daripada menyiksa dan mencela sebab hanya akan mematahkan hati.

${ }^{25}$ Ibid, 264.

178 | TamaddunVol. 7 , No. I, Januari - Juni 2019 
3. Memberikan contoh yang baik kepada anak dengan menjadikan uswah hasanah bagi murid. Hal tersebut sebab anak-anak akan gampang mengikuti jejak gurunya. Tradisi adalah salah satu faktor yang kuat dan tercepat dalam pendidikan, khususnya pada fase kanak-kanak.

4. Anak-anak juga dilatih instingnya untuk bergaul dengan orang lain dan bermasyarakat. Mereka masih senang untuk berlomba-lomba, hal ini penting untuk melatih kebiasaan yang baik, mendidik akhlak, dan menggerakkan cita-cita.

5. Membiasakan dan melatih perbuatan yang baik untuk anak. Pembentukan tradisi pada saat ini sangat penting bagi pembiasaan diri tepat waktu dan menyukai kebenaran. $^{26}$

Penggunaan media pembelajaran untuk menunjang aktivitas pembelajaran masih belum memadai atau minim. Media pembelajaran kuttab dahulu masih tradisional. Belum ada papan tulis dan bangku meja, hanya memakai kertas dan batu tulis apa adanya. Murid-murid duduk bersila menghadap guru. Pelajaran diberikan dengan dibacakan oleh guru dan diulang membacanya oleh murid-murid atau didiktekan oleh guru dan ditulis oleh murid atau murid disuruh menyadur dari buku yang sudah ditulis sebelumnya. $^{27}$

Pada masa permulaan pemerintahan Abbasiyah metode pendidikan dan pengajaran yang dipakai bisa dikelompokkan menjadi tiga macam cara yakni, yaitu:

1. Metode lisan, berupa diskusi, qiraat, ceramah (al-sama), dan dikte (imla').

2. Metode menghapal adalah ciri umum pendidikan sekarang ini. Murid-murid mesti membaca secara berulang-ulang pelajarannya sehingga pelajaran ini tertanam di benak mereka. Sehingga dalam proses berikutnya murid akan mengkontekstualisasikan dan mengeluarkan kembali pelajaran yang dihapalnya sehingga dalam perdebatan dan diskusi murid bisa merespon, memunculkan sesuatu yang baru atau mematahkan lawan.

3. Metode menulis, dianggap metode yang paling penting pada masa ini. Metode ini ialah penjiplakan karya-karya ulama, sehingga terjadi proses intelektualisasi hingga

\footnotetext{
${ }^{26}$ Fahmi, op. cit, h. 64-70
}

${ }^{27}$ Yunus, op. cit, h. 51 
level penguasaan ilmu murid semakin meningkat. Selain itu juga, sebagai instrumen penggandaan buku-buku teks, sebab pada saat ini belum ada mesin cetak, dengan pengkopian buku-buku, kebutuhan terhadap teks buku sedikit banyak teratasi. ${ }^{28}$

Kuttab umumnya dibangun di luar masjid, namun kadangkala didirikan di dalam masjid, sebab kekurangan tempat di luar masjid. Walaupun begitu ada juga guru-guru yang mengajar anak-anak di bilik-bilik masjid atau penjuru-penjuru yang berkaitan dengan masjid. ${ }^{29}$ Situasi lingkungan belajar kuttab dapat dikatakan seadanya, hal ini jelas berbeda dengan pendidikan anak-anak pejabat maupun orang-orang kaya.

\section{F. Evaluasi}

Berhubungan dengan bentuk evaluasi pembelajaran di kuttab, tidak ditemukan penjelasan yang ditail. Hanya saja ketuntasan dalam menghafal al-Qur'an atau pelajaran lain yang menjadi ukuran tercapainya tujuan pembelajaran. Anak yang rajin dan cerdas akan segera meneruskan pelajarannya dan cepat selesai ilmunya. Sedangkan anak yang malas dan bodoh tentu akan mempunyai waktu yang lama dalam menuntaskan pembelajaran al-Qur'an. Waktu belajar di kuttab tidak mempunyai batasan yang ditentukan. Tergantung dari seberapa kecerdasan dan rajin yang dimiliki oleh murid agar dapat segera menyelesaikan pelajarannya dan cepat tamat ilmunya. ${ }^{30}$

Pada pelajaran yang diberikan kepada murid secara individual, tidak bisa dibatasi oleh waktu dan bergantung pada situasi murid. Penetapan lama belajar hanya khusus bagi pelajaran yang mempunyai kelas-kelas (klasikal). Akan tetapi umumnya waktu belajar pada kuttab kurang lebih selama 5 tahun. ${ }^{31}$

\section{G. Jenis-jenis Kuttab}

Kuttab berkembang pesat sesudah masa pemerintahan Dinasti Ummayah, akan tetapi selaras dengan perluasan wilayah kekuasaan Islam, populasi umat Islampun

\footnotetext{
${ }^{28}$ Samsul Nizar. Sejarah Pendidikan Islam: Menelusuri Jejak Sejarah Pendidikan Era Rasulullah Sampai Indonesia. (Jakarta: Kencana, 2013), h. 114.

${ }^{29}$ Yunus, op. cit, h. 48-49.

${ }^{30} \mathrm{Ibid}$, h. 54.

${ }^{31} \mathrm{Ibid}$, h. 55.
} 
semakin bertambah. Keadaan ini menuntut didirikannya banyak kuttab di berbagai wilayah tersebut untuk memberikan pendidikan dasar bagi umat Islam sejalan dengan laju pertumbuhan umat Islam yang sangat cepat. Pada perkembangannya, disamping kuttab yang ada di masjid, ada juga kuttab-kuttab umum yang berbentuk madrasah, yaitu sudah memakai gedung sendiri terpisah dari masjid dan dapat menampung ribuan siswa.

Kuttab semacam ini mulai berkembang sebab adanya pengajaran khusus untuk anak-anak keluarga kerajaan, pegawai-pegawai Istana, dan pejabat-pejabat pemerintah. Dan diantaranya yang mengembangkan pengajaran secara khusus ini ialah Hajjaj bin Yusuf al-Saqafi (w. 714) yang pada awalnya menjadi muallim untuk anak-anak Sulaeman bin Na'im, Wazir Abdu al-Malik bin Marwan.

Menurut Ahmad Syalabi bahwa ada dua jenis kuttab dalam sejarah pendidikan Islam. Perbedaan ini khususnya dilandaskan kepada kurikulum (isi pengajaran), guru dan waktu pertumbuhannya.

1. Kuttab jenis pertama ialah kuttab yang berperan dalam mengajarkan membaca dan menulis dengan teks dasar puisi-puisi Arab, dan dengan sebagian besar gurunya ialah non-Muslim (minimal pada zaman permulaan Islam).

2. Kuttab jenis kedua ialah kuttab yang berperan sebagai lembaga pengajaran al-Qur'an dan dasar-dasar ajaran Islam. Di sinilah, terjadinya kesalahan pemahaman oleh sejumlah ilmuwan terdahulu, dengan memandang kedua jenis kuttab ini adalah sama. Contoh tiga orang sejarawan, yaitu Ignaz Goldziher, Ahmad Amin, dan Philip K. Hitti. Mereka meyakini bahwa membaca dan menulis al-Qur'an serta dasar-dasar agama diajarkan di kuttab yang sama semenjak zaman perkembangan Islam yang paling awal akan mengarah kepada pemahaman bahwa anak-anak generasi awal mempelajari agamanya dari orang-orang yang bukan muslim.

Di sinilah signifikansi perbedaan kedua jenis kuttab tersebut menjadi terlihat jelas. Kuttab jenis kedua tidak ditemukan di zaman perkembangan Islam paling awal, saat kuttab jenis pertama telah mulai berkembang. Pengajaran al-Qur'an di kuttab baru 


\section{Novianti Muspiroh}

mulai sesudah jumlah yang mampu membaca dan para penghafal al-sudah banyak. Sebelumnya pengajaran agama anak-anak dilakukan di rumah-rumah secara non formal.

Jumlah umat Islam yang mampu membaca dan menulis serta menguasai al-Qur'an berkembang sangat cepat, seiring dengan semangat ilmiah yang tinggi dan berkurangnya ketergantungan kepada guru-guru non Muslim. Hal ini ditambah dengan kontak orang-orang Islam dengan pusat-pusat aktivitas ilmiah di luar Arabia selama dan setelah penaklukan. Hanya kira-kira sepuluh tahun sesudah wafatnya Nabi Muhammad saw, kaum muslimin sudah menguasai Mesir, Irak, Syria, dan wilayah-wilayah yang menjadi pusat aktivitas ilmiah saat itu. Kejadian tersebut mendorong lahirnya perluasan ilmu pengetahuan yang dikenal oleh orang-orang Islam dan pada akhirnya mempengaruhi kurikulum kuttab. Perkembangan selanjutnya memperlihatkan bahwa aritmatika (berhitung dasar), gramatika bahasa Arab, al-Qur'an, puisi, membaca dan menulis menjadi bagian penting dari kurikulum pendidikan di lembaga ini.

Anak-anak akan terus belajar di Kuttab sampai menyelesaikan hafalan alQur'annya sebagaimana Imam As-Syafii saat belajar di Kuttab. Akan tetapi apabila tidak sanggup, boleh sebagiannya. ${ }^{32}$

Sejumlah referensi Abad Pertengahan menginformasikan bahwa yang saling berbeda mengenai usia anak mengikuti pendidikan di kuttab. Mungkin hal itu bisa juga dinilai sebagai kenyataan tidak adanya ketentuan yang baku. Seorang Ilmuwan Andalus, yaitu Ibn Hazm (w. 456/1064) berpendapat bahwa usia lima tahun ialah usia ideal untuk mengawali pendidikan kuttab. Umumnya usia anak yang belajar di Kuttab adalah sejak dini, dimulai dari usia 5 tahun sampai 12 tahun. Namun tidak menutup kemungkinan apabila ada yang lebih dari 12 tahun.

Ibn al-Jawzi (w. 597/1200) menceritakan bahwa ia mulai belajar di kuttab pada usia enam tahun, namun banyak dari teman-teman sekelas-nya yang lebih tua darinya. Seorang ulama bernama Ibn al-'Adim pertama belajar di kuttab di usia tujuh tahun. Sementara yang lain bahkan menunggu sampai berusia sepuluh tahun. Hal tersebut

\footnotetext{
${ }^{32}$ Abdullah Nasih Ulwan. Al-Tarbiyah fi al-Islam. (Sukoharjo, Jawa Tengah: Insan Kamil, 2010), h.130
} 
memperlihatkan tidak adanya kesamaan ketentuan batas awal usia seorang anak masuk pendidikan di kuttab.

Walaupun demikian umumnya anak-anak belajar di kuttab sejak usia dini, maka salah satu perhatian dari Kuttab ialah menjaga keselamatan anak-anak. Selanjutnya kuttab menyusun kaidah atau aturan-aturan tertentu agar melindungi mereka dari penyakit sosial atau akhlak dan penjagaan itu mencakup seluruh hal seperti waktu istirahat kuttab, dan dari pergi hingga pulang.

Ketidaksamaan usia ini juga terjadi pada fokus materi pembelajaran yang diberikan. Hal tersebut tergantung kepada pertimbangan ulama-ulamanya atau gurugurunya dan kebutuhan daerah tertentu. Berikut ini ialah catatan Ibn Khaldun (w. 808/1406) tentang pendidikan kuttab pada zamannya, yang memperlihatkan perbedaanperbedaan tersebut di empat wilayah. (1) Orang-orang Islam di Maghrib (Maroko) sangat memfokuskan pada pengajaran al-Qur'an. Anak-anak wilayah ini tidak akan belajar materi yang lain sebelum mempelajari dan menguasai al-Qur'an dengan baik. Pendekatan pembelajaran ialah dengan pengelanan satu bentuk kata dalam hubungannya dengan bunyi bacaan. Pendekatan ini dinamakan pendekatan ontografi. Itulah mengapa, menurut Ibn Khaldun, orang-orang Islam di Maroko mampu menghafal al-Qur' an lebih baik dari orang-orang Islam di wilayah manapun. (2) Orang-orang Islam di Andalusia (Spanyol). Kuttab wilayah ini lebih mengutamakan membaca dan menulis. Al-Qur'an tidak diprioritaskan dibandingkan dengan bahasa Arab dan puisi. Berbeda dengan kuttab di Maroko, Penekanan belajar adalah pada kemampuan menyalin dan membaca al-Qur'an tanpa mesti menghafalnya. (3) Daerah Afrika Utara, yaitu Tunisia, sebagian Algazay, dan sebagian Libya. Menurut Ibn Khaldun, di daerah-daerah tersebut, pendidikan dasar di kuttab lebih mengutamakan al-Qur'an dengan prioritas terutama pada variasi atau ragam bacaan (qira'at); kemudian diikuti dengan hadits dan seni kaligrafi. (4) Daerah keempat menurut Ibn Khaldun ialah daerah Timur, yang meliputi Semenanjung India, Asia Tengah, Iran, dan Timur Tengah (al-Masyriq) yang menurut pengakuannya tidak ia ketahui secara jelas dibandingkan dengan tiga wilayah yang pertama. Secara umum daerah Timur ini memiliki kurikulum dengan materi beragam dan campuran, dengan al-Qur'an sebagai pokok materi, namun tidak 


\section{Novianti Muspiroh}

menggabungkannya dengan pengajaran seni tulis indah atau kaligrafi, akibatnya tulisan tangan anak-anak Muslim dari Timur tidak terlalu baik.

Terlepas dari kondisi yang tidak sama di atas, kuttab berkembang dengan cepat sejak zaman permulaan sejarah peradaban Islam. Ia berkembang yang menyelaraskan kepada banyak latar belakang budaya. Dari lembaga dengan belasan siswa pada awalnya, kuttab, di banyak tempat, menjadi institusi tempat belajar ribuan siswa, masih di akhir abad pertama Hijriyah. Kuttab yang dipimpin oleh Abu al-Qasim al-Balkhi (w. 105/723) di Kufah diinformasikan memiliki 3.000 peserta didik. Berkembangnya lembaga kuttab, mungkin bisa dibayangkan dari berita dari seorang pengembara, Ibn Hawqal (w. 367/977). Saat dia mengunjungi Palermo, Sisilia, di sana ada sekitar 300 guru kuttab, satu kenyataan yang menunjukkan adanya ratusan kuttab di kota ini. Palermo hanyalah sebuah kota kecil jika diperbandingkan dengan Kairo, Samarkand, Jerussalem, Istanbul, Aleppo, Damaskus, atau Baghdad. Pada Abad Pertengahan, ada banyak kuttab di Kairo, seperti kuttab yang dibangun di Majmu'ah al-Ghauri di Kairo pada $900 \mathrm{H}$, menyediakan akomodasi dan asrama untuk para siswanya. Di wilayah ini juga ada kuttab yang berkaitan dengan satu institusi; pendidikan tinggi yang secara tidak langsung tentunya membantu keberlangsungan pendidikan siswa-siswa lulusannya ke tingkat yang lebih tinggi.

Ahmad Syalabi berpendapat ada dua jenis Kuttab dalam sejarah pendidikan Islam. Perbedaan beberapa jenis Kuttab tersebut ditinjau dari isi kurikulum, guru-guru, dan masa tumbuhnya.

1. Kuttab yang berperan mengajarkan membaca dan menulis dengan teks dasar puisipuisi Arab. Mayoritas para pengajarnya ialah bukan orang Islam. Kuttab jenis ini berkembang pada zaman permulaan Islam.

2. Kuttab yang berperan sebagai lembaga pendidikan yang mengajarkan al-Qur'an dan dasar-dasar agama Islam.

Meskipun demikian, pada umumnya jenjang pendidikan di kuttab dibagi menjadi 2 tingkatan, yaitu (1) kuttab awwal: pada tingkatan ini anak-anak belajar berhitung dasar, ilmu dasar agama, menghafal al-Qur'an, menulis, dan membaca. (2) Kuttab 


\section{Novianti Muspiroh}

qonuni: pada tingkatan ini anak-anak dan remaja belajar adab dan ilmu bahasa. Mereka juga belajar hadits, ilmu agama, dan banyak ilmu yang lain.

\section{H. Kuttab di Berbagai Wilayah Islam}

Esksistensi kuttab berada di berbagai wilayah kekuasaan Islam, dari wilayah Barat (al-Magrib) sampai wilayah Timur (al-Masyrik), yaitu:

1. Kuttab di wilayah Timur (al-Masyriq), Semenanjung India, Asia Tengah, Iran, dan Timur Tengah. Kuttab sendiri banyak terdapat di daerah Timur, sebagaimana dicatat oleh Ibnu Jubair pada tahun ke 7 hijriah. Diberitakan bahwa banyaknya kuttab dikarenakan perhatian Shalahuddin al-Ayubi yang memerintahkan Syam dan Mesir saat itu dalam pendidikan anak-anak. Dimana juga disebutkan bahwa di Damaskus terdapat salah satu kuttab besar untuk anak-anak yatim.

2. Kuttab di wilayah Afrika Utara (Ifriqiyah), yaitu sebagian Libya, sebagian Algazy, dan Tunisia. Kuttab di wilayah ini memfokuskan pada ragam qira'at (bacaan) kemudian diikuti hadits dan kaligrafi.

3. Kuttab di Andalusia (Spanyol)

Kuttab di wilayah tersebut memprioritaskan membaca dan menulis al-Qur'an tidak diprioritaskan dibandingkan dengan bahasa Arab dan puisi. Penekanan pada pelajaran menulis melahirkan ahli-ahli kaligrafi yang bisa menyalin dan membaca alQur'an tanpa mesti manghafalnya (seperti muslim Maroko)

4. Kuttab di Maroko (Maghrib)

Umat Islam di Maghrib sangat memfokuskan kepada pengajaran al-Qur'an. Siswasiswa di wilayah tersebut tidak akan belajar materi yang lain sebelum menguasai alQur'an dengan baik. Pendekatan yang dipakai ialah pengenalan satu bentuk kata dalam kaitannya dengan bunyi bacaan (pendekatan ontografi). Inilah mengapa, menurut Ibnu Khaldun, orang-orang Islam di Maghrib bisa menghafal al-Qur'an lebih baik dari muslim wilayah manapun. 


\section{Novianti Muspiroh}

Umumnya Kuttab di wilayah ini memiliki kurikulum campuran dengan al-Qur'an sebagai inti, namun tidak mengintegrasikannya dengan keterampilan kaligrafi, sehingga tulisan tangan siswa-siswa muslim dari wilayah timur tidak begitu baik.

\section{Perkembangan Kuttab}

1. Kuttab di Zaman Nabi Muhammad saw

Di Kuttab ini diajarkan membaca dan menulis dengan teks dasar puisi-puisi Arab. Pembelajaran di Kuttab diselenggarakan di rumah guru-guru. Setelah orangorang Islam hijrah ke Madinah, pembelajaran di kuttab tersebut dilaksanakan pada masa Nabi Muhammad saw dengan bertempat di rumah guru dan masjid. Fungsi kuttabpun dibagi menjadi dua jenis, (1) mengajarkan membaca menulis dan (2) mengajar dasar-dasar agama Islam dan al-Qur'an.

2. Kuttab di masa Khulafa al-Rasyidin

Sebagaimana halnya di masa Nabi Muhammad saw yang memusatkan pendidikan di kuttab, maka begitu juga yang terjadi pada masa khalifah Abu Bakar Sidiq. Kuttab tetap dipertahankan sebagai institusi tempat belajar menulis dan membaca. Eksistensi kuttab sejalan dengan pembangunan masjid, dan guru di Kuttab ialah sahabat-sahabat Nabi Muhammad saw.

3. Kuttab di masa Dinasti Umayyah

Pendidikan Kuttab yang mengajarkan menulis dan membaca al-Qur'an dan materi agama Islam yang lain tetap diteruskan di masa Umayyah. Hanya saja tempatnya selain di rumah guru dan masjid juga dilaksanakan di istana. Kuttab di istana bertujuan mengajarkan siswa-siswa dari keluarga yang berada di istana Khalifah. Guru istana disebut muaddib. Pendidikan istana mengajarkan adab sopan santun, membaca, menulis, riwayat hukama, syair, hadits, dan al-Qur'an. 


\section{Novianti Muspiroh}

4. Kuttab pada masa Dinasti Abbasiyah

Pada masa ini, kuttab menyebar ke banyak wilayah seiring dengan tersebarnya agama Islam. Tradisi mengajar al-Qur'an di kuttab telah dilakukan, dimana Imam alBaihaqi dalam Manaqib Imam Syafi'i menjelaskan bahwa Imam Syafi'i pada mulanya belajar di kuttab sebelum melakukan rihlah ilmiyah.

5. Masa kentemporer,

Penyebutkan kuttab masih populer, dimana tercatat bahwa Syeikh al-Qaradhawi ketika masih kanak-kanak belajar al-Qur'an di kuttab, dalam buku biografi ulama Mesir yang kini menetap di Qatar ini, yang berjudul "Yusuf al-Qaradhawi: Ibnu Qaryah wa al-Kuttab.

\section{J. Syarat menjadi Guru Kuttab}

Tidak setiap orang bisa mengajar di Kuttab, karena ia mesti memenuhi persyaratan yang diminta pihak manajemen kuttab. Masyarakat sangat berhati-hati dalam memilih guru bagi anak-anaknya untuk belajar di kuttab. Mereka akan mencari guru yang memiliki akhlaq yang mulia, kepribadian baik, dikenal dengan istiqomah dalam beribadah, adil serta mempunyai kemampuan yang baik dalam penguasaan alQur'an dan ilmu-ilmunya. Bahkan al-Qubisi mensyaratkan agar guru berwibawa namun akrab serta lembut terhadap anak-anak, tegas tidak galak, tidak berwajah cemberut, marah tidak ramah, dan tidak kasar. Yang paling penting adalah ia mampu mendidik adab anak-anak ke arah yang lebih baik. ${ }^{33}$ Disamping itu, disyaratkan bagi guru agar memiliki kesholehan, memiliki sifat amanah, hafal al-Qur'an, tulisannya bagus, menguasai ilmu hitung dan lebih diprioritaskan lagi yang telah menikah atau berkeluarga.

\section{K. Pembiayaan Kuttab}

Berdasarkan jejak historis pendidikan kuttab, persoalan pembiayaan telah tertulis dengan rinci dan rapih. Pembiayaan kuttab dilakukan oleh para orangtua yang mengamanahkan pendidikan anaknya di kuttab. Mereka memberikan uang kepada

\footnotetext{
${ }^{33}$ Sahnun, op cit, h. 47.
} 


\section{Novianti Muspiroh}

pengelola kuttab yang akan dibayarkan untuk gaji guru dan keperluan kuttab lainnya. Untuk persoalan gaji guru, diberikan setiap bulan atau per paket atau per tahun. Ada juga orangtua kaya yang menanggung pembayaran keluarganya yang tidak mampu atau dapat pula orang yang tidak bisa bukan dari keluarganya.

Ini adalah gambaran ajaran-ajaran Islam, potret saling menolong dan kebersamaan dalam meringankan beban biaya orang yang tidak mampu. Hal ini juga akan meringankan beban negara dari pembiayaan pendidikan, sebab dalam sejarah kuttab, ada wilayah-wilayah yang hanya membiayai biaya pendidikan kuttab secara terbatas. Adapun biaya kuttab dapat ditanyakan kepada manajemen kuttab yang bersangkutan. Sebab mungkin semua kuttab mempunyai kebijakan yang berbeda dalam persoalan keuangan. Baik segi waktu ataupun jumlah.

\section{Kuttab sebagai Lembaga Pendidikan bagi Kaum Terpinggirkan}

Eksistensi kuttab memiliki kedudukan yang mulia dan agung di hati masyarakat Islam ketika itu, karena Kuttab ialah tempat utama di dunia Islam. Tempat di mana anak-anak belajar mengenai adab, ilmu-ilmu agama, mengenal lebih dalam mengenai Iman, al-Qur'an dan pengenalan-pengenalan terhadap Allah. Dahulu kuttab berlangsung di rumah-rumah para guru (mu'addib, mu'allim) atau pekarangan sekitar masjid.

Umumnya, kuttab tidak hanya lembaga belajar al-Qur'an bagi anak-anak, akan tetapi di tempat itu mereka mendapatkan santunan berupa makanan, pakaian serta keperluan lainnya, dimana kuttab sangat memperhatikan keadaan miskin dan anak-anak yatim. Terkait dengan ini, seorang ulama yang bernama al-Haytami mengeluarkan fatwa bahwa kuttab harus menjadi lembaga pengayom anak-anak yatim. ${ }^{34}$

Seiring dengan itu, mulailah berdiri banyak kuttab yang diperuntukkan bagi anakanak yang tidak mampu, anak-anak yatim, anak tentara atau anak-anak pengangguran yang dasarnya mereka tidak mempunyai kemampuan untuk masuk di kuttab. Hal ini dimaksudkan untuk menjaga mereka dalam mengenalkan dan belajar ilmu-ilmu agama (At-Ta'lim fi Mishr zaman Al-Ayyubiyin hal.121). Dalam sejarah Kuttab tertulis, pada

\footnotetext{
${ }^{34}$ Bosworth, op cit, h. 34; Hassan dan Jamaluddin, op cit, h. 195.
} 


\section{Novianti Muspiroh}

zaman dinasti al-Zankiyyin, al-Ayyubiyin dan al-Mamalik, Kuttab yang khusus anak yatim mendapat perhatian khusus. Bahkan, Nuruddin al-Zanki ketika menjadi khalifah, ia mendirikan kuttab bagi anak-anak yatim dan memberikan gaji guru-gurunya dengan gaji yang tinggi. (Ar-Raudhatain fi Akbar Al-Daulatain hal.54)

\section{Penutup}

Pendidikan kuttab dipandang sebagai pendidikan dasar bagi anak-anak guna menciptakan generasi Islami semenjak usia dini. Hal ini sebagaimana terlihat dari muatan materi dan proses pembelajarannya. Figur seorang guru di dalamnya berperan sangat penting sebagai permodelan atau contoh bagi perilaku peserta didik di kuttab.

Lembaga kuttab ini lahir murni dari inisiatif swadaya masyarakat tanpa adanya intervensi pemerintah yang tergerak untuk mendidikan anak-anak generasi Islam dalam literasi dan ajaran-ajaran agama. Walaupun demikian, masih ada muatan-muatan pelajaran yang lain sebagai pelengkap. Perannya begitu besar terlebih di awal-awal kemunculan agama Islam, dalam pemberantasan buta huruf.

Disamping itu, eksistensi kuttab adalah sebagai sebuah terobosan untuk mengakomodir pendidikan bagi kaum terpinggirkan, dalam hal ini terutama anak-anak yatim. Upaya ini termasuk pula pemenuhan kebutuhan-kebutuhan penunjang pendidikan. Dengan demikian kuttab melebihi dari sekedar lembaga pendidikan dasar non formal yang menekankan kepada pendidikan karakter. 


\section{Referensi}

Bosworth, Clifford Edmund, M. S. Asimov. 2000. The Age of Achievement: A.D. 750 to the End of the Fifteenth Century: The Achievements: History of Civilizations of Central Asia. Paris, France: UNESCO.

Burke, Edmund. 2009. "Islam at the Center: Technological Complexes and the Roots of Modernity", dalam Journal of World History, University of Hawaii Press, 20 (2), June 2009: 165-186.

Chaer, Moh. Toriqul. 2015. "Kuttab, Lembaga Pendidikan Islam Klasik”, dalam Jurnal alMurabbi, Vol. 01 No. 02, Januari-Juni 2015.

Corbin, Henry. 2014. History Of Islamic Philosophy. Abingdon, United Kingdom: Routledge.

Coulson, Andrew J. 2009. Delivering Education. California, USA, Stanford University: Hoover Institution.

Fahmi, Asma Hasan. 1979. Sejarah dan Filsafat Pendidikan Islam. Jakarta: Bulan Bintang.

Fahrussin, M. Mukhlis. 2010. "Kuttab: Madrasah pada Masa Awal (Umayyah) Pendidikan Islam”, dalam Jurnal Madrasah. Vol. II, No. 2 Januari-Juni, 2010.

Gibb, H. A. R. (1960-1985). The Encyclopedia of Islam, vol. 8. Leiden: Brill.

Grunebaum, Gustave E. Von, Katherine Watson. 2005. Classical Islam: A History, 600 A.D. to 1258 A.D., diterjemahkan oleh Katherine Watson. Piscataway, New Jersey: Aldine Transaction.

Gutas, Dimitri. 1998. Greek Thought, Arabic Culture: The Graeco-Arabic Translation Movement in Baghdad and Early 'Abbāsid Society (2nd-4th/8th-10th Centuries). London, United Kingdom: Psychology Press.

Hassan, Muhammad Hassan dan Nadiyah Jamaluddin. 1984. Madaris al-Tarbiyahfi'alHadarah al-Islamiyah. Kairo: Dar al-Fikr al-Arabi.

Holt, P. M., Ann K. S. Lambton, Bernard Lewis. 1977. The Cambridge History of Islam Volume 1. Cambridge, UK: Cambridge University Press.

Hyman and Walsh. 2010. Philosophy in the Middle Ages. (Hackett Publishing: Indianapolis.

Jabalah, Amir Jad Allah Abu. 1998. Tarikh al-Tarbiyah wa-al-Ta'lim fi Sadr al-Islam. al$\mathrm{Mu}$ allif.

Khalili, Jim Al-. 2011. 5: The House of Wisdom. The House of Wisdom: How Arabic Science Saved Ancient Knowledge and Gave Us the Renaissance. London, United Kingdom: Penguin Publishing Group.

Makdisi, George. 1992. “Typology of Institution of Learning”, dalam al-Anthology Studies oleh Issa J. Baulatta. Montreal: McGill Indonesia IAIN Development Project. 
Meri, Josef W., Jere L. Bacharach. 2006. Medieval Islamic Civilization: An Encyclopedia. (Abingdon, United Kingdom: Routledge.

Nashabe, Hisham, 1989. Muslim Educational Institution. Beirut: Librarie De Liban.

Nizar, Samsul. 2013. Sejarah Pendidikan Islam: Menelusuri Jejak Sejarah Pendidikan Era Rasulullah Sampai Indonesia. Jakarta: Kencana.

Panji Masyarakat. 1997. Yayasan Nurul Islam.

Pormann, Peter E., Savage-Smith, Emilie. 2007. Medieval Islamic Medicine. (Washington, D.C.: Georgetown University Press.

Robinson, Francis, "Review: Law and Education in Medieval Islam: Studies in Memory of Professor George Makdisi", dalam Journal of the Royal Asiatic Society, diedit oleh Joseph E. Lowry, Devin J. Stewart and Shawkat M. Toorawa. Cambridge University Press, 18 (01) 2008: 98-100.

Sahnun, Muhammad ibnu. 256H. Adab al-Mu'allim. Dar al-Lu'luh.

Sirjani, Raghib As-. 2011. Sumbangan Peradaban Islam Pada Dunia. Jakarta: Pustaka AlKautsar.

Syalabi, Ahmad. 1987. Al-Tarbiyah al-Islamiyah, Nuzumuha, Falsafatuha, Tarikhuha. Kairo: Maktabah al-Nahdah al-Mashriyah.

Tafsir, Ahmad, 2004. Cakrawala Pemikiran Pendidikan Islam. Bandung: Mimbar Pustaka.

Ulwan, Abdullah Nasih. 2010. Al-Tarbiyah fi al-Islam. Sukoharjo, Jawa Tengah: Insan Kamil.

Yunus, Mahmud. 1990. Sejarah Pendidikan Islam: Dari Zaman Nabi Muhammad saw Khalifah-khalifah Rasyidin, Umaiyah dan Abbasiyah sampai Zaman Mamluks dan Usmaniyah Turki. Jakarta: PT. Hidakarya Agung. 
Novianti Muspiroh

192 | TamaddunVol. 7 , No. I, Januari - Juni 2019 